\title{
Weapons of War or Ravages of Nature? Investigating the Use of CBW
}

\author{
Marie Isabelle Chevrier University of Texas at Dallas, USA
}

$\mathbf{T}$ he article by Peter Barss is a valuable contribution to the existing literature on the investigation of the use of chemical, biological, or toxin weapons (CBW). ${ }^{1} \mathrm{He}$ constructs detailed procedures to investigate allegations of the use of any of these weapons from the perspective of epidemiology theory. Barss reviews the investigations of the alleged use of toxin weapons ("yellow rain") in Laos and Cambodia, the use of chemical weapons by both sides in the Iran-Iraq war, and the use of chemical weapons by Iraq against its own Kurdish population. He argues persuasively that these inquiries would have been conducted more effectively if the teams had followed standard procedures for field investigations according to epidemiology theory.

This is precisely the kind of expert advice that policymakers need from the scientific community. The process of confirming that a country has violated international agreements and international law by using CBW has a vital technical component. The evidence of violation must withstand the scrutiny of the international scientific community before a sound political judgment can be rendered. Barss's thorough model of investigation would meet that test. The political consequences of deficient investigations are clearly demonstrated in the case of yellow rain.

Missing from Barss's analysis, however, is a description of the protocol developed by the United Nations (UN) for the investigation of the use of CBW. Govern-

Marie Isabelle Chevrier is Assistant Professor of Political Economy, School of Social Sciences, GR-31, University of Texas at Dallas, Richardson, TX 75083-0688, USA. Dr. Chevrier, who holds a $\mathrm{PhD}$ in public policy from Harvard University, was a founding member of the Chemical and Biological Weapons Working Group at the Center for Science and International Affairs at the John F Kennedy School of Government. She was also the principal author of the Federation of American Scientists report, Proposals for the Third Review Conference of the Biological Weapons Convention (1990). ment officials will want to know the differences between the two methods of investigation and why Barss's model is preferable.

Unfortunately, Barss's review of the investigations of Iraqi use of chemical weapons against its own Kurdish minority demonstrates some of the limitations of his recommendations. In large part because neither Iraq nor Turkey would allow an official UN investigation, the investigations that did take place occurred after a long intervening period. However, even though the investigations did not follow Barss's epidemiological model very closely, few, if any, knowledgeable members of the international community harbor any doubts that Iraq used chemical weapons against the Kurds. The Kurdish case shows that while Barss's procedures may be desirable, not all of them are necessary to establish the requisite proof of violation. Perhaps Barss's argument should be that investigators should show good faith and follow as many of the procedures as time and circumstances permit.

Moreover, taken together, the cases of yellow rain and the gassing of the Kurds illustrate one of the great dilemmas of trying to prove violations of the Geneva Protocol. Barss states that "the principle of 'innocent until proven guilty' seems obvious enough," but unfortunately the standard of proof to establish guilt is not universally agreed upon. Is it "beyond a reasonable doubt," the same standard of proof for a criminal prosecution? If so, those who make the political judgment as to whether the scientific evidence constitutes such proof run the risk that some violators will literally get away with murder. On the other hand, if the standard of proof is less stringent, innocent countries may be judged guilty and may suffer political, and perhaps economic, consequences. Statisticians will recognize the impossible task of trying to minimize both Type I and Type II errors simultaneously.

Although Barss occasionally distinguishes among investigations of the alleged use of chemical, biological, 
and toxin agents as weapons, he inappropriately groups the three of them together all too often. For example, in discussing the evidence that Egypt used chemical weapons against Yemen, he says that "since there is relatively little documentation available for this and other reports of $C B T W$ during the conflict between Egypt and Yemen, they will not be discussed" (emphasis added). He states earlier that Egypt is reported to have used chemical weapons in Yemen, but nowhere does he claim that anyone raised allegations of the use of biological or toxin agents of warfare as the quoted section implies. Similarly, he states that "the UN investigating team did not provide convincing support for the Iraqi allegation of CBTW used by Iran." It is important to note that Iraq alleged the use of chemicals only, not biological or toxin agents. Barss talks in several places about investigations of CBTW use; however, his examples include no investigations of alleged use of biological agents.

By lumping the three types of agents together, he may give a false and unintended impression that the procedures for investigating the possible use of these three different types of weapon are the same. However, because chemical agents never occur naturally, investigating the use of chemical weapons is easier in many respects than investigating the use of biological or toxin weapons. To establish the use of biological agents or toxins, one must not only prove that the agent in ques- tion affected troops or population, but that the agent was deliberately disseminated-that it did not occur naturally. Although Barss states that only one welldocumented case of chemical poisoning could provide sufficient evidence of the use of chemical weapons, he does not highlight the unique investigative challenges posed by each type of weapon.

Other minor inaccuracies in the article will likely irritate the diplomatic audience that Barss most needs to reach. For example, he is not careful to distinguish between the deployment of chemical weapons and their use. He uses the two terms synonymously. Moreover, careful reading of the text of the Biological Weapons Convention reveals that the convention does not prohibit the use of biological and toxin weapons per se; rather, it prohibits their acquisition, possession, development, stockpiling, and transfer. These types of errors in understanding of the political dimension of CBW may tend to undermine Barss's credibility, even though his scientific credentials appear unassailable.

\section{Note}

1. Barss uses the acronym CBTW for "chemical, biological and toxin warfare." I will talk about the use of chemical, biological, and toxin weapons. In order to differentiate the two, I will use the acronym CBW.

\title{
Toxic Weapons, Epidemiology, and Human Rights
}

\author{
Howard Hu Harvard University, USA
}

$\mathbf{I}$ n June of 1991, a team of experts from the UN Special Commission (UNSCOM) inspected an Iraqi facility at Samarra, known as the "Muthanna State Enterprise for Pesticide Production." Its inspection re-

Howard $\mathrm{Hu}$ is Assistant Professor of Occupational Medicine in the School of Public Health, Channing Laboratory, Harvard Medical School, 180 Longwood Ave, Boston, MA 02115, USA and is Associate Physician in the Brigham and Women's Hospital, Boston, Massachusetts. He is an epidemiologist and occupational/environmental medicine specialist. Dr. Hu is author or coauthor of three articles on chemical weapons. He has been on two investigative missions; the first to investigate the possible toxic effects of tear gas in South Korea in 1987, and the second to investigate the alleged use of lethal chemical weapons against the Kurds of northern Iraq in 1988. Dr. Hu is a member of the Board of Directors of Physicians for Human Rights, an impartial fact-finding organization dedicated to using medical skills to defend human rights. vealed a chemical weapons factory (United Nations, 1991). Inspectors found mustard gas and organophosphorus nerve agents, types GB and GF, as well as tabun-agent GA (CBW News, 1991). They estimated that the facility had the capacity to produce 2.5 tons of sarin and 5 tons of mustard gas per day. According to media reports, "dozens" of companies were implicated in the construction and production processes of the facility, including companies originating from Austria, France, Germany, India, Switzerland, the United States, and seven other countries (CBW News, 1991; Independent, July 17, 1991).

Meanwhile, a June 10, 1991 press report emerged from an investigation by the Thai Interior Ministry and military intelligence into the possible use of chemical weapons by Lao forces against hilltribe rebels (FBISEAD-91-110, June 7, 1991). On May 23, 1991, a clandes- 